\title{
Gubernamentalidad del miedo en México y Colombia
}

\author{
Governmentality of fear in México and Colombia
}

Alexandra Agudelo López ${ }^{1 \otimes}$

Fecha correspondencia:

Recibido: septiembre 9 de 2016.

Revisión: diciembre 14 de 2016.

Aceptado: diciembre 15 de 2016.

Forma de citar:

Gil, C. (2017). Gubernamentalidad del miedo

en México y Colombia. Rev. CES Derecho., 8(1),

100-123.

Open access

Términos de uso

Licencia creative commons

Ética de publicaciones

Revisión por pares

Gestión por Open Journal System

DOI: http://dx.doi.org/10.21615/cesder.8.1.5

ISSN: 2145-7719

Sobre el artículo:

El presente artículo es resultado de la

investigación Fobopolítica, rúbricas de una

gubernamentalidad contemporánea, presentada

para optar al título en el Doctorado en Ciencias

Sociales, Niñez y Juventud, de la Universidad de

Manizales y la Fundación Centro Internacional

de Educación y Desarrollo Humano-CINDE. La

investigación fue culminada en julio de 2016

1. Abogado, especialista en derecho procesal de

la Universidad de Antioquia.

Sobre los autores:

1. Doctora en Ciencias Sociales, Niñez y

Juventud de la Universidad de Manizales y la

Fundación Centro Internacional de Educación

y Desarrollo Humano-CINDE. Magister en

Educación de la Pontificia Universidad

Javeriana.

\section{Comparte}

\section{Resumen}

El presente artículo se interroga sobre ¿Cómo ha llegado el miedo a convertirse en el aspecto definitorio de los procesos de gubernamentalidad en México y Colombia?

Y asume que la expansión del miedo es más una forma de gubernamentalidad contemporánea, que un problema con origen único en el sujeto. A través de las estrategias foucaultianas de eventualización y problematización, y mediante la herramienta analítica del dispositivo, se hace posible comprender que se trata una fuerza estratégica capaz de engendrar otras formas de construcción de realidad.

Además, en estos primeros años del siglo XXI se ha usado la seguridad como consolidación del miedo en tanto gubernamentalidad. El texto concluye con una idea que vertebra la tesis: Un sujeto con miedo no está perdido, está atrapado y este atrapamiento puede definirse a través de una forma de gubernamentalidad: Fobopolítica.

Palabras clave: Miedo, gubernamentalidad, eventualización, problematización, fobopolítica.

\section{Abstract}

This paper asks about: how the fear has become in the most relevant aspect into the governmentality process in Mexico and Colombia? Also, it takes over that the fear expansion is due to a contemporary governmentality and it is not only a subjective problem. The research process was based on the strategies of eventalization and problematization proposed by Michael Foucault, and using the device analytical tool from the same author, to understand that the fear is a strategy force to build other kinds of reality. On the other hand, during the first decade in XXI Century, the security has been use to fear consolidation through the governmentality device. The conclusion is that a person is not lost if he lives afraid. He is trap and that situation could be defined through a new way of governmentality: Fobopolitic.

Keywords: Fear, governmentality, eventualization, problematization, fobopolitics

\section{Introducción}

El interés político-académico de la investigación que sustenta el presente artículo, comenzó con la problematización de las condiciones en las que el miedo se usa políticamente en dos países latinoamericanos como son México y Colombia y los efectos que tiene en los procesos de subjetivación de las comunidades de ciudad Juárez y Medellín. 
El siglo XX y el comienzo del XXI han sido testigos de la pérdida de densidad en el poder soberano y protector de los estados, de su capacidad para responder a la garantía de derechos, el debilitamiento en la preservación del bienestar de sus gentes, la fragilidad para contrarrestar la corrupción y la maleabilidad con la que se asume el orden constitucional, lo que de suyo ha implicado un detrimento creciente en la legitimidad y confianza por parte de las poblaciones. En el caso de México y Colombia, la emergencia de poderes paraestatales, insurgentes y derivados del narcotráfico refleja este histórico y progresivo achicamiento del Estado y los efectos del permanente acomodamiento de los modelos financieros que dirigen el planeta.

Por lo anterior, la investigación realizada en estos países entre los años 2010 - 2015 y que se ocupó de problematizar los diversos usos políticos de miedo, no solo tuvo como foco los procesos de recomposición de los Estados, también fue necesaria una mirada sobre otros poderes (paraestatales, delincuenciales y del narcotráfico) que pugnan el control de las poblaciones y los territorios a través de refinadas prácticas teñidas por el terror y el empleo intencionado del miedo. De la misma manera y como posibilidad de hallar alternativas de salida a la compleja situación que viven las ciudades de Juárez y Medellín, el trabajo de campo se ocupó de algunos procesos de resistencia que emprenden las comunidades, especialmente organizaciones y colectividades juveniles en defensa de sus derechos, la dignidad y la vida.

En un primer esfuerzo epistémico, la investigación se ocupó en recuperar los hitos que en la teoría política han visibilizado, opacado y renombrado el miedo como un elemento clave en la configuración del Estado y de los contratos sociales que han dado lugar a las matrices societales y de gubernamentalidad contemporáneas. Así, basado en una idea del Estado como síntesis de relaciones de poder, cuya principal función es la regulación de los sujetos, la importancia de este marco para los fines argumentativos de la investigación reside en una postura crítica que intenta develar que, los lugares de visibilidad que ha ocupado el miedo en la historia, están fuertemente articulados con el ejercicio del poder y particularmente, con la producción de ciertos tipos de subjetivación. De este modo, resulta posible aseverar que en los momentos en que el miedo ha sido destituido discursivamente de la relación con la política, es quizá donde más influencia fáctica ha tenido en la producción social. No se trata por tanto de un ejercicio de linealidad historiográfica, por el contrario, lo que pretende es resaltar, desde algunas producciones teóricas emblemáticas, el lugar que el miedo tiene en la constitución de procesos de gubernamentalidad.

Metodológicamente, la tarea investigativa se desarrolló con base en las estrategias de eventualización y problematización propuestas por Foucault y en especial, en la herramienta del dispositivo de miedo, categoría analítica producida a partir de las teorizaciones de Foucault, Deleuze y Agamben. La conjugación de estas estrategias permitió configurar un método de estudio de dispositivos, de gran utilidad para abarcar la complejidad socio-política que caracteriza los territorios y la difícil condición que experimentan los habitantes de Ciudad Juárez y Medellín.

Con lo anterior, los procesos de eventualización y problematización operaron con los enunciados provenientes del conjunto de saberes, prácticas, relaciones mediante las cuales el miedo tiene lugar en los contextos de ciudad Juárez y Medellín, los efectos que tiene en la producción de subjetividad y en la configuración de procesos de gubernamentalidad local y nacional. En este apartado de la investigación, se empleó críticamente la información con el propósito de develar las continuidades 
y discontinuidades, las regularidades y las rupturas que hacen del miedo un factor determinante de la vida política de las comunidades.

Es cardinal indicar que fue a partir de los ejercicios de eventualización y problematización, que se logró hacer emerger importantes comprensiones que permitieron comenzar a trazar las rúbricas de un proceso de más amplio espectro como es el uso global del miedo definido en la forma de Fobopolítica.

\section{Nuevos eventos de un viejo problema}

\section{La localización de una discontinuidad no es otra cosa que la verificación de un problema a resolver.}

\section{Michel Foucault}

Los acontecimientos violentos acaecidos en lo corrido del siglo XXI y con efectos a escala planetaria, han reavivado el interés por los estudios sobre el miedo en las ciencias sociales. De manera singular, los fenómenos de terror, muerte y criminalidad que han ocurrido en América Latina y el Caribe, la inscriben como uno de los escenarios más fecundos para las investigaciones respecto del uso del miedo en la gestión de las poblaciones.

Y es que el miedo, esa emoción conocida por todo ser humano y experimentada con frecuencia por los pobladores que habitan contextos de desigualdad extrema como lo son algunos países latinoamericanos, emerge ahora con una renovada fuerza proveniente de una sincronía de actores y eventos que vigorizan su rol en la política y en la configuración de las sociedades. Se trata, como afirma Bauman citando a Lagrange de un "miedo derivativo que orienta su conducta (tras haber reformado su percepción del mundo y las expectativas que guían su elección de comportamiento) tanto si hay una amenaza inmediatamente presente como si no" (2007, p. 11). Esta clase de miedo inaugura al menos dos aspectos con rebote directo en las formas de la política contemporánea, de un lado, aunque se lía con sucesos locales, tiene un fuerte sello global en el que encuentra su mayor poder de desestabilización del sujeto y de otro, conlleva una fuerte carga de desconfianza en el futuro.

En el primer caso, se trata de miedos que combinan las historias locales con prácticas globales, demandando como lo han sugerido Robertson (2003) y Beck (2006) una ineludible referencia a procesos de producción glocalizada en los estudios sobre el miedo. Para Robertson (2003, p.269) la importancia de una perspectiva glocalizada en los estudios sobre el miedo en las ciencias sociales radica en la posibilidad de superación de las dicotomías universal/particular en aras de explicaciones más amplias, profundas y reales de los problemas que hoy afronta la humanidad. Insiste en que solo es posible abordar la complejidad de fenómenos como los que hoy presencia la humanidad, con análisis de cara a las realidades micro y macro sociales sin apelaciones de jerarquía permanentes. Por su lado, Beck advierte que las sociedades de riesgo global en las que habitamos, reflejan incertidumbres que han sido fabricadas (2006, p.6) provocado dislocación en las convencionales formas de poder, que lo trasladan hacia otros actores, contextos y procesos que subvierten las relaciones establecidas entre agentes y agenciados. Una forma clara de esta fractura puede hallarse en los desplazamientos del poder estatal al capital económico y financiero que, inexorablemente reconfiguran interacciones y transacciones produciendo nuevas lógicas glocales, con profundo impacto sobre nuestros miedos. 
La sociedad del riesgo afirma Beck, exige una apertura del proceso de decisión, no sólo del Estado, sino también de las corporaciones privadas y de las ciencias (2006. p.7) tanto como de los modos como percibimos nuestras emociones sobre el mundo.

La segunda consecuencia de esta forma actualizada del miedo, está asociada a un incremento en la sensación de vulnerabilidad, riesgo y desprotección de las comunidades y los sujetos, debido a una excepcional expansión mediática que ha logrado convencer al mundo que el peligro está en todas partes y puede hacer víctima a cualquiera, lo que acarrea significativas consecuencias para la construcción colectiva de futuro y la confianza en las instituciones. De esta manera, la relación directa o indirecta con la violencia, esto es, por la vivencia del acontecimiento o a través de la interacción mediática, implicará para los sujetos una interiorización de una visión del mundo en la que el miedo cobrará un lugar cada vez más protagónico, tiñendo su subjetividad y calibrando sus conductas con base en el temor a los peligros y a los otros. Esta es quizá la repercusión más importante de la reactualización del miedo, ya que no se trata de una emoción con origen en la incapacidad de los sujetos para afrontar la existencia, sino de un "miedo como medio para amedrentar a las personas y someterlas y, que puede estar vinculado a un gran número de sistemas políticos con los que estamos familiarizados" (Arendt, 2012, p.124).

Ambas consecuencias, la de miedos producidos glocalmente y la de un miedo forjado en los sujetos con fines de dominio, advierten sobre un resurgimiento del miedo en la esfera política, especialmente en lo que concierne a capacidad de detonar cambios drásticos en la forma de organización social y de impulsar medidas de control que de otra forma serían impensables. Podría esto advertir que ¿estamos en momentos de configuración y reconfiguración política del miedo y de sus usos en la gestión contemporánea de las poblaciones?

Por mucho tiempo el miedo perdió el destacado papel que Hobbes le había asignado en la teoría política y de manera particular en la formación del Estado moderno, localizándose en la esfera de los estudios psicológicos y sociológicos del comportamiento humano, estrechamente vinculado a los sentimientos de cobardía y a la manera de afrontar la vulnerabilidad que produce la inseguridad. En su mayoría, los estudios sobre el miedo lo ubican como un sentimiento negativo, nocivo al desarrollo del ser humano y es por ello que existen muchas investigaciones, algunas derivadas de la psicología cognitiva y del comportamiento (Bandura 1971-1997; Gardner 19952011; Goleman 1996-2014) que sustentan que el miedo opera como un inhibidor de diversas conductas, por ejemplo en el caso de las fobias, por lo que se requiere que este sea tratado a través de métodos de moldeamiento sistemático que faciliten su extinción (Bandura, 1991). Estos enfoques han sido durante mucho tiempo fuentes privilegiadas para el análisis del miedo, el terror, la angustia y los comportamientos de aislamiento, pasividad e indiferencia que experimentan los seres humanos, desplazando cada vez más explicaciones de tipo político que pueden coadyuvar en una comprensión más amplia, por lo tanto más histórica de la creciente manifestación de este fenómeno del miedo colectivo. Esta individualización del miedo, es incluso notoria en estudios filosóficos como los de Nussbaum, que apelan a la superación del miedo mediante la combinación de estrategias de tolerancia y empatía que pueden lograrse en una expansión de las capacidades subjetivas. De acuerdo con esta autora, para quien el miedo es una emoción narcisista a superar, "necesitamos tener antes que nada, el compromiso socrático (y cristiano-kantiano) necesario para examinar nuestras elecciones y comprobar si son egoístas" (2013, p. 290). 
Este fuerte acento individual que expresa una tendencia a comprender las causas y síntomas del miedo sin apego a factores externos de carácter social, cultural o político, ha tenido su derivación en una progresiva despolitización del miedo, algo que Delumeau (2012) denomina un sospechoso silencio sobre el miedo en la historia y una vertiginosa expansión en la esfera de la responsabilidad del sujeto. Y es que con frecuencia se encuentra que los análisis hobbesianos o maquiavélicos son desacreditados por suponer que las formas de gobierno contemporáneo han superado la apelación al miedo como factor de cohesión social o regulación, sin embargo los hechos demuestran que las prácticas políticas del nuevo siglo, las que provienen del Estado y las que inauguran otros actores y poderes de la contienda sociopolítica y económica mundial, han hallado en él un interesante mecanismo para obtener sus propósitos, provocando una propagación del miedo en todas las esferas de la vida pública y privada.

En lo que a la práctica del Estado se refiere habría que comenzar por reiterar su progresivo achicamiento, secuela del acomodamiento a los modelos de mercado que regulan las economías mundiales. Este resquebrajamiento sistemático de los Estados, en simultáneo con la presencia creciente de sectores privados que asumen su responsabilidad en el manejo de los recursos, la protección de los pobladores y la defensa de los territorios, se ha desarrollado en medio de un clima de incertidumbre y miedo en el que la oferta de seguridad adquiere su mayor valor político-estratégico. Así, desahuciadas de la promesa de protección y bienestar del Estado y en evidente condición de vulneración por la falta de garantías sociales, las comunidades se ven arrojadas a una nueva forma de seguridad que limita todos los derechos y libertades, ya sea las ofrecidas por los gobiernos (restrictivas, punitivas y de control) o los agentes privados (coercitivas, abusivas y pagadas). Esta condición de miedo extremo, de acuerdo con Angarita "puede ser aprovechada para ofertar seguridad y, como contraprestación, exigir mayor intensidad en el control y dominio sobre las personas" (2011, p. 91). Este protagonismo que adquiere la seguridad como forma de contrarrestar la violencia, el terrorismo, la vulnerabilidad que experimentan las sociedades, no es en lo absoluto fortuito o exclusivo de prácticas políticas situadas, por el contrario representan una forma de reactualización de las sociedades de seguridad (Foucault, 2004) con un espectro de influencia más amplio marcado por el uso político del miedo y la gestión de las poblaciones facturado al avivamiento del capitalismo.

De esta manera, deslegitimado y achicado el Estado, el acumulado histórico de las prácticas de seguridad, entendidas estas como gestión política de las poblaciones queda a disposición de otras fuerzas paraestatales o no estatales que le emplean en tanto mecanismo de recorte de derechos, privación de libertades y expansión de la dominación, a decir de Shearing y Wood (2007) por esta vía, los agentes privados se incorporan a los procesos de configuración social, operando de manera mayormente descentralizada, más que jerárquica, formando una variedad de nodos, entre ellos unidades paramilitares, caudillos locales, pandillas criminales, fuerzas policiales, grupos mercenarios y también ejércitos regulares, que ofertan seguridad en variadas formas. Uno de los aspectos que devela esta compleja situación en la que el miedo opera como medio y la seguridad como fin, está asociado a lo que el mismo Foucault denominaría redes del poder, un proceso que desborda los límites jurídicos y se instala como dominio sobre la vida, y cuyo desafío radica en "distinguir los acontecimientos, diferenciar las redes y los niveles a que pertenecen, y reconstruir los hilos que los unen y los hacen engendrarse unos a otros" (2007, p.144). 
Acercando un poco más la mirada sobre el problema, dos Estados como México y Colombia estampados con el sello de ilegitimidad, corrupción e ineficiencia, dejan serias dudas sobre su capacidad para garantizar la protección de las poblaciones y bastantes indicios sobre la manera como se emplea políticamente el miedo para hacer transformaciones, bajo supuestas políticas de seguridad. Esta destitución del carácter de Estado protector, se ha hecho más evidente aun, de un lado, porque ha quedado demostrada su inoperancia en el monopolio de la fuerza, y de otro porque la ciudadanía ha emprendido acciones de justicia privada que en muchas regiones de ambos países, cuentan con el respaldo de los habitantes. En adición el poder del narcotráfico ha penetrado la estructura de estos Estados, reduciendo las posibilidades de una gestión política con justicia y sin impunidad.

La enviciada gestión pública de los gobiernos en México y Colombia, ha provocado enormes estancamientos en la construcción democrática del proyecto de nación, radicalizado las confrontaciones políticas y debilitado las funciones que por definición le corresponden al Estado en materia de derechos humanos, un costo social que han debido asumir las poblaciones en detrimento de una calidad de vida, ya en si misma empobrecida. Por lo que los dos países enfrentan serios desafíos en términos de la gobernanza democrática, que deben ser asumidos con urgencia, so pena de desatar una crisis humanitaria de proporciones incalculadas para el futuro cercano.

Contrario a ello, las políticas de seguridad que se han implementado en los últimos años (Seguridad pública en México y Seguridad democrática en Colombia) desdibujan la confluencia de factores sociales y relaciones de poder que producen el mismo fenómeno de la inseguridad y se enfocan en discursos tecnocráticos y medidas militarizadas y represivas que acentúan el problema. Las políticas de seguridad en ambos países se niegan a reconocer que la inseguridad constituye la expresión de condiciones políticas, sociales, económicas y culturales, que teniendo su fuente en la producción histórica del proyecto de nación, la desencadenan en tanto síntoma como un comportamiento tendiente a la afectación de unos a favor de otros. Desconocen además, que no se trata solamente de conductas criminales, referidas a la violencia de sujetos contra sujetos, toda vez que como lo expresa Carrión violencia y delito (criminalidad) no son símiles, en tanto el primero desborda porque contiene al segundo (Carrión, 2009, p. 10) que la inseguridad está referida también a la representación que puede tenerse de dinámicas de poder que afectan la posibilidad de despliegue de la personalidad o a condiciones territoriales, físicas, geográficas que mantienen en vilo a una comunidad respecto de su desarrollo vital y supervivencia.

Tampoco incorporan las políticas de seguridad la idea que la inseguridad es una construcción social, política y cultural que detona en el sujeto la angustia frente a la existencia, un sentimiento cada vez más expansivo y generalizado de amordazamiento, aprensión, sospecha y desconfianza frente a las dinámicas sociales, económicas y políticas que, sumada a la pérdida de sentidos colectivos e individuales desencadena en una profunda sensación de vulnerabilidad, parálisis e impotencia para afrontar la construcción de horizontes comunes. Por ello, las medidas tecnológicas, armamentistas y militaristas tienen un efecto regulativo de corta duración que rápidamente detonan en condiciones de inseguridad más graves. A decir de Angarita y para ilustrar lo que sucede en América Latina tanto en el ámbito gubernamental como de la ciudadanía,

el enfoque de seguridad militarista o securitario es el predominante, no solo en las políticas oficiales sino también incluso en la mente de los ciudadanos, quienes hacen 
eco de la visión que reduce la seguridad al ámbito de lo biológico-personal y que discrimina y señala la responsabilidad de esta en cabeza de unos cuantos. (2013. p. 123)

Esta comprensión parcializada y ciertamente intencionada de las políticas de seguridad, ha generado a decir de Carrión (2009) aumentos en los delitos, en los homicidios que se han incrementado significativamente en México y Colombia, la percepción de inseguridad se ha elevado, los fenómenos de victimización y revictimización se han disparado y la legitimidad de los Estados es cada vez más difícil de sostener. De ahí que pueda señalarse para ambos casos que

los grandes errores de la implementación de las políticas de seguridad han sido el peso asignado al delito sobre la violencia, a lo operativo sobre lo trascendental, a los empírico sobre lo teórico, a la víctima sobre el victimario, a la violencia sobre el desempeño institucional y a las políticas represivas de los gobiernos sobre la seguridad. (Carrión, 2009. p. 11)

Lo que de manera casi directa indica que la reducción de la seguridad a un tema lucha contra el crimen y el desconocimiento de las recomendaciones de las Naciones Unidas en materia de seguridad humana, no son una coincidencia.

Para resaltar esa hipótesis, vale señalar que el Centro de Estudios por la Paz J.M. Delàs ${ }^{1}$ presentó en el año 2011 un estudio sobre el problema del Militarismo en América Latina en el que señala respecto al Plan Mérida en México que esta iniciativa, formulada como plan de emergencia para la lucha contra el narcotráfico y el crimen organizado, recibió desde el año 20081.600 millones de dólares para ser ejecutados hasta el 2011, de los cuales 1.400 millones estaban destinados a México con el propósito de "mejorar los programas de las agencias de seguridad en la vigilancia de los territorios; dotar de equipamiento y activos para apoyar a las agencias de seguridad; entregar nuevas tecnologías para fortalecer la coordinación de las fuerzas de seguridad e información entre México y EEUU" (2010, p.19). La lucha contra el narcotráfico que ha sido fortalecida con inversiones de esta magnitud, no ha afectado significativamente las estructuras del narco, por el contrario, ha develado la connivencia entre fuerzas del Estado y los carteles, al punto que reforzar el sector militar, no se traduce de ninguna manera en reducción del negocio de las drogas, En palabras de Valenzuela, lo que iniciativas como el Plan Mérida ha generado en

México son más cateos domiciliarios, más cárteles judiciales y militares, más conculcación de los espacios privados de las personas, más ejecuciones, más muerte, más miedo, más secuestros, más extorsiones. El gobierno sacó al ejército a cumplir labores policiales y la guerra se le ha ido de las manos. (2011. p. 176)

En el caso de Colombia, el Plan Colombia (heredero de la doctrina de seguridad nacional) permitió en su segunda etapa cuando en la presidencia del país se encontraba Álvaro Uribe Vélez la gestación y desarrollo de la política de seguridad democrática, afincada en dos ejes: el fortalecimiento de la confianza inversionista y la cohesión social ajustada estrictamente al fortalecimiento tecnológico y militar para la implementación del Plan Patriota. Entre 2000 y 2005 el plan Colombia recibió una cifra estimada por el Departamento de Defensa de Colombia de 4.500 millones de dólares, a la cual se le adicionaron 463 millones a través de la Iniciativa Andina contra las Drogas y 90 millones más para la financiación de fuerzas militares extranjeras, ambas asignadas por solicitud de la administración Bush. Lo que 
convertía a Colombia para ese entonces, según el informe, en el tercer receptor de ayuda económica militar en el mundo tras Israel y Egipto. "Esto sumado al gasto regular en defensa y seguridad, que incrementó en un 80\% en 2009 (10.055 millones de dólares) lo que equivale al 5.2\% del PIB de la nación" (2010, p. 11). Estas políticas de seguridad democrática, erigidas sobre conceptos como el de guerra preventiva, ha desarrollado su acción fundamentalmente desde la restricción de derechos de la población, lo cual ha desencadenado una grave situación en la que a cambio de lograr una disminución sustantiva de la violencia y la criminalidad, basada en la prevención socio económica y estructural, se ha recurrido a una forma totalmente contraproducente de prevención situacional mediante el incremento de la represión y el uso desmedido de la tecnología que inexorablemente ha producido mayor violencia.

En adición a lo anterior, un número recurrente de investigaciones (Kessler, 2010; Ugarte, 2011; Angarita, 2012, 2013; Maldonado, 2012; Alvarado \& Serrano, 2012) indican la ineficacia de las políticas de seguridad en México y Colombia en términos de responder a las condiciones de desigualdad, violencia y desarrollo humano que demandan las comunidades, lo que podría indicar que las llamadas Seguridad pública y Seguridad democrática han sido fundamentadas y discursivamente presentadas sin ese propósito, y que su real intención ha sido siempre la de allanar el terreno para el fortalecimiento del modelo neoliberal sin apego alguno a las definiciones de seguridad como soberanía y protección.

En contraposición, podría afirmarse que existe un campo de acción en el que dichas políticas han sido efectivas en ambos contextos, la manipulación mediática, el fortalecimiento de las fuerzas militares y su dotación, la tecnificación de la vigilancia que han permitido el seguimiento, persecución y represión de las poblaciones sobre todo aquellas que hacen parte de la oposición y que han desatado las alarmas frente al uso de la Seguridad como una forma expansiva de gubernamentalidad.

\section{Estrategias analíticas para la comprensión del miedo y de sus usos políticos}

\section{El Método es precisamente la elección de los hechos.}

Henri Poincaré

Para comprender las profundas relaciones que tiene el miedo con la política contemporánea y los efectos de sus usos en los actuales procesos de gubernamentalidad, la investigación acogió dos estrategias analíticas desarrolladas por Foucault, la eventualización y la problematización, como vías de aproximación al presente desde la lectura del pasado. Ambas estrategias retomadas en investigaciones y trabajos académicos recientes (Chakrabarty, 2000; Castro-Gómez, 2008; Restrepo, 2008; Morey, 2014; Deleuze, 2013/2014/2015) demostraron el inmenso potencial que tienen para los abordajes genealógicos y arqueológicos del pasado y su consecuente comprensión de las realidades presentes.

Este aspecto resultó crucial para la aspiración argumentativa de la investigación, en tanto permitió desocultar las prácticas discursivas y no discursivas que han posibilitado la institución del miedo como impronta en las prácticas políticas contemporáneas y su rebote en la configuración de subjetividades tanto como de procesos de subjetivación política. Como se mostrará a continuación y de acuerdo con Restrepo 
(2008, p. 115) la importancia de ambos procedimientos analíticos radica tanto en que constituyen el amarre de la arqueología y la genealogía, como el horizonte filosófico y político de la obra de Foucault.

Es importante resaltar que en tanto estrategias analíticas, la eventualización y la problematización están signadas por la complejidad que procede del esfuerzo de hallar en cada evento no las regularidades que forzosamente lían el presente, sino las profundas comprensiones de la cadena de acontecimientos que le hacen materia de despliegue histórico y protagónica aparición actual. Por lo que no se trata de un ejercicio analítico simple, toda vez que está relacionado con acciones que remueven en los finos detalles hasta encontrar los delgados hilos que suturan el presente.

La elección de ambas estrategias - eventualización y problematización - no sólo da cuenta de una apuesta metodológica en el sentido de un abordaje investigativo que permita develar la sucesión de acontecimientos que han dado lugar al uso político del miedo, también entraña un propósito académico relacionado con el desocultamiento de aquello que se ha dado por verdad respecto del miedo, la producción de un saber que le ha emplazado en el mundo de las emociones y ha otorgado la responsabilidad de su resolución a la valentía y la osadía personal. Es por este saber profundamente arraigado en la historia, que se supone tarea de los sujetos la respuesta al miedo, su eliminación, pero también es por ello que su expansivo poder ha sido usado para instalar nuevas representaciones y transformaciones económicas, políticas y sociales de dimensiones planetarias sin que se desaten las alarmas. De ahí que como lo formulara Foucault una de las funciones teórico - políticas de la eventualización implica una ruptura de las evidencias, aquellas evidencias sobre las que se apoyan nuestro saber, nuestros consentimientos, nuestras prácticas (1982, p. 61).

La eventualización implica un ejercicio de interrogación radical a los acontecimientos, elaboraciones históricas, discursos y saberes que se han configurado como verdad, tanto como a las prácticas que han permitido que se naturalicen y se conviertan en elementos estructurantes de la vida cotidiana. Es decir, no se trata exclusivamente de cuestionar los hechos tanto como de develar los diferentes modos mediante los cuales han alcanzado su estatuto de verdad y han producido ordenes de realidad sobre los que se erigen las subjetividades y más aún nuevos procesos de subjetivación. Las prácticas por tanto constituyen una de las herramientas más importantes de la eventualización, ya que opera como bisagra que articula los discursos con aquello que producen como acción. "estos tipos de prácticas no están únicamente dirigidos por la institución, prescritos por la ideología o guiados por las circunstancias - sea cual fuere el papel de unas y otras - sino que poseen hasta cierto punto su propia regularidad, su lógica, su estrategia, su evidencia, su razón" (Foucault, 1982, p. 59).

Un proceso de eventualización implica a decir de Restrepo, una sospecha radical y una lucha permanente sobre los conceptos y supuestos que tienden a tomarse como evidentes y que en general se mantienen fuera de examen, implica un procedimiento de acercamiento cauteloso a otros horizontes de historicidad y a los propios buscando entender en sus singulares amarres un suceso o series de sucesos específicos (2008, p. 116).

De ahí que en la búsqueda de cimientos que soportan las que damos por verdad, la eventualización se instituye como uno de los principios clave del método arqueológico y le otorga al ejercicio hermenéutico una fuente importante de acontecimientos 
para la deliberación. Esta potencia de la eventualización, ha de reiterarse, le abona al estudio del miedo y de sus usos políticos un valor excepcional, toda vez que usada para desocultar una discontinuidad, hará posible comprender aquello que ha permitido este paso tan apresurado (Foucault, 1982, p. 60) en relación con la gestión de las poblaciones y descomunal consolidación de un escenario sociopolítico y económico como el que experimentamos en la actualidad.

Es evidente, que existe un desafío metodológico al pretender problematizar el refinamiento con el que hoy por hoy se emplea el miedo para gatillar cambios en el orden cultural y sobre todo en las representaciones colectivas y al tiempo evitar un asociacionismo vulgar con otros acontecimientos y teorizaciones que en la vida política moderna y contemporánea reciente le han empleado como instrumento de transformación. Es por ello que a consideración de Restrepo, los principales riesgos que han de tenerse en cuenta cuando se emplea la eventualización como estrategia analítica se asocian al presentismo histórico y la indagación metafísica. El primero tiende a sobreponer las categorías interpretativas del presente sobre el pasado anulando toda posibilidad de singularización y la segunda hace emerger constantes históricas a partir de la aspiración de interpretación (2008, p, 117). Ambas dan muestra de violencias epistémicas y constituyen riesgos frente a los cuales se debe estar alerta.

Así, manteniendo vigilancia sobre el peligro de violencia epistémica, el uso de la estrategia analítica de eventualización tuvo presente actores y teorías que han producido discursos sobre el miedo, pero más aún, tuvo presente la producción de prácticas que, generadas de manera discursiva y no discursivas mediante un acontecimiento, se han convertido en la forma más empleada, pero también la más aceptada de usar políticamente el miedo. Conforme con lo expresado por Foucault, este análisis de los regímenes de prácticas requiere considerar las programaciones de conducta, que tienen a la vez unos efectos de prescripción en relación a lo que está por hacer (efectos de jurisdicción) y unos efectos de codificación en relación a lo que está por saber (efectos de veridicción) (1982, p. 59).

De este modo, la configuración del proceso de eventualización a partir del análisis de regímenes de prácticas que incorporaran acontecimientos, conductas y efectos relativos a la acción y el conocimiento, involucró para el caso del uso político del miedo una interesante caja de herramientas ${ }^{2}$ que permitieron abordar la historicidad de un elemento que más que una emoción, configurando una clave para comprender la política contemporánea, tanto como las prácticas que le han elevado a la categoría de condición política necesaria para la institución del Estado, el desarrollo de la economía, la lucha contra el terrorismo, el narcotráfico y la obtención de la seguridad en sus múltiples expresiones.

Lo anterior, derivó algunas preguntas al ejercicio de eventualización ¿Cómo se ha convertido el miedo en un elemento indispensable de la práctica política contemporánea? ¿A qué debe su alto valor estratégico en lo que a control y gestión de las poblaciones se refiere? ¿Cómo puede ser el miedo éticamente reprochable y políticamente comprensible? Quizá de ese modo sea posible rastrear el camino y hallar las singularidades que generen las comprensiones que se requieren respecto del miedo en tanto acontecimiento y su uso como discontinuidad.

2 La idea de una teoría que sirva a modo de caja de herramientas, está fundamentada en Foucault en dos aspectos: primero que, "no se trata de construir un sistema sino un instrumento. una lógica propia a las relaciones de poder y a las luchas que se comprometen en ellas" (...). Segundo, "que esta búsqueda no puede hacerse más que poco a poco, a partir de una reflexión (necesariamente histórica en algunas de sus dimensiones) sobre situaciones dadas" (2007. p. 101) 
Es por lo anterior, que la eventualización implicó para la investigación una posibilidad de "encontrar conexiones, encuentros, apoyos, bloques, relaciones de fuerza, etc., que en un determinado momento, han formado lo que luego funcionará como evidencia, universalidad, necesidad" (Foucault, 1982, p. 61), es decir, el uso de estas estrategias en tanto método, hicieron posible hallar los efectos de jurisdicción y veridicción que tienen los regímenes de prácticas sobre el miedo, que a su vez lo convierten en un elemento sustancial para la instalación de un nuevo orden, a partir del cual se hace posible su naturalización histórica y su condición de dado por verdad.

\section{Trazos de una gubernamentalidad del miedo en México y Colombia}

Como se mencionara al comienzo del presente texto, el principal propósito ético-político de la investigación consistió en visibilizar el miedo como elemento de importancia estratégica en la política y de manera singular, mediante su incorporación en la gestión de poblaciones en las ciudades de Juárez - México y Medellín - Colombia en el periodo 2010 - 2015. Para alcanzar este cometido, se eventualizaron y problematizaron prácticas discursivas y no discursivas mediante las que el miedo se ha usado políticamente en estos países, procediendo arqueológicamente de la formación histórica definida para el periodo 2010 - 2015, a la configuración de los discursos mediante el análisis polimórfico de los enunciados de cada uno de las fuentes. Para lograr el criterio de materialidad de los enunciados, en lo que respecta a prácticas de gobierno, se construyó un archivo basado en discursos gubernamentales, de orden nacional y local (planes de desarrollo, políticas de seguridad y programas sectoriales) y para comprender los usos del miedo por parte de otros actores (paramilitarismo, autodefensas, narcotráfico, delincuencia) se operó a partir de enunciados de entrevistas, narrativas y multimedias, registros audiovisuales obtenidos durante el trabajo de campo con representantes de gobiernos locales, integrantes de la academia, colectivos juveniles, líderes comunitarios y otros miembros de la comunidad. Estas acciones - configuración del archivo, selección de enunciados y la búsqueda de recurrencias enunciativas - permitieron comprender los regímenes de verdad en torno a los cuales giran los juegos de veridicción y jurisdicción de una gubernamentalidad basada en el miedo, que comenzamos a denominar Fobopolítica.

\section{Ciudad Juárez, el fin justifica los miedos.}

"Porque aquí son más de dos años, que se están cometiendo asesinatos, se están cometiendo muchas cosas y nadie hace nada."_M1³

Como compleja, agitada y trágica puede definirse la condición que hoy enfrenta el proyecto político de México. Y es que pese a ser un país que se ha caracterizado por luchas internas y externas siempre vigentes, también habría que señalar que la segunda mitad del Siglo XX posicionó al país como uno de los más prolíficos económica y socialmente de América Latina. No obstante, el comienzo del siglo XXI y en especial los últimos cinco (5) años, han situado a México en el foco de los debates académicos y políticos, producto de la enmarañada articulación entre los poderes del Estado con el narcotráfico y la creciente emergencia de fuerzas de autodefensas en diversos lugares del territorio nacional. Lo que ha conducido a un vertiginoso aumento de la corrupción, la deslegitimación de la autoridad, la expansión de la violencia y a la redefinición del control sobre las regiones en función del multimillonario mercado de las drogas. Todo esto ha dejado cada vez más hundida a la población en un panorama de violencias, abusos y muertes que México solo podría comparar con los históricos momentos de su Revolución. 
Este fenómeno de violencias, enfrentamientos y progresiva deslegitimación democrática es el resultado de múltiples eventos en su mayoría asociados al narcotráfico y a la disputa por territorios de privilegiada importancia para el tránsito y la comercialización de la droga. Pero estos hechos también vinculan al gobierno (Felipe Calderón en el sexenio 2006-2012 y Enrique Peña Nieto 2012-2018) y a las fuerzas del Estado como responsables de la corrupción, la impunidad y la connivencia con el narcotráfico, lo que sido clave en el escalamiento de las violencias, especialmente, en la expansión de los crímenes selectivos a periodistas, defensores de derechos humanos y jóvenes (como es el caso de los 43 estudiantes de la Normal Rural Raúl Isidro Burgos de Ayotzinapa en 2014).

En el Índice de paz en México producido por el Instituto para la economía y la paz para 20154, señala como desde 2003 hasta 2014 se presentan en el país una serie importante de eventos, no lineales pero sí correlacionados que expresan la complejización del fenómeno de la violencia, a la vez que evidencian el involucramiento de los gobiernos y las fuerzas del Estado en el agravamiento de crisis. Sin embargo, la imagen oculta uno de los aspectos que más podría favorecer la comprensión dinámica de las violencias, esto es tanto de la exacerbación de los homicidios como de la aparente pacificación de los territorios, se trata de la disputa entre los cárteles de la droga o de su hegemonía. Este hecho es vertebral para dimensionar el protagonismo de este actor en la situación que hoy enfrenta México, tanto como para identificar la ineficacia de la guerra contra el narco y los diversos programas que se han desplegado para combatirlo. Adicionalmente, es necesario señalar que el ocultamiento de este evento, trae como consecuencia el desconocimiento del componente económico de la guerra, no solo en el sentido del negocio del narcotráfico, sino del negocio de la guerra en sí misma. De acuerdo con el Índice de paz, el gasto de la política de lucha contra el narco este país para el año 2014 asciende a más de 3 billones de pesos (USD 233.000 millones) un equivalente del 17.3\% del PIB nacional, lo que demuestra que se trata de un lucrativo aspecto del modelo económico global.

Es este resuelto crecimiento del narcotráfico y las diversificaciones en el negocio de las drogas que al convertirlo en una fuente incontrolable e incalculable de dinero le permiten instalarse como el gran poder económico, social y político en México. Los últimos 30 años del pasado siglo, el tema del tráfico de drogas en México era apenas una relación que empezaba a tejerse con Colombia, pero que sería solo el comienzo de una larga historia de colaboraciones mutuas entre los cárteles. Para los años 80 y 90 el despliegue del narcotráfico en Colombia tenía ya un sello distintivo y las relaciones con los cárteles mexicanos se habían convertido en la más potente forma de expansión del mercado. Sin embargo, como señala Chabat durante este tiempo y pese a la evidencia de grupos ya consolidados en el tráfico de drogas en México, "este no era un tema de la discusión pública ni un punto de conflicto con la comunidad internacional" (2012, p. 22). Pero sería precisamente la relación con Colombia, especialmente a través del cartel de Medellín y del progresivo tráfico de cocaína hacia los Estados Unidos, que los cárteles de la frontera norte de México encontrarían la fuente de su desarrollo económico y político, con su correlato, el control de las ciudades y la poblaciones.

Para alcanzar el lugar que hoy ocupan los cárteles de la droga en las ciudades de la frontera norte, especialmente en ciudad Juárez, se requirió un estrecho vínculo con los diversos poderes del Estado, por lo que rápidamente los dineros del narcotráfico fueron a parar a las campañas, las fuerzas militares y policiales de la ciudad, per- 
meando y pervirtiendo la función de autoridad, protección y justicia del Estado en la región. Estas intrincadas relaciones entre el Estado y el narcotráfico han demostrado que más que un negocio de minorías empobrecidas el negocio de las drogas se ha instalado - casi desde sus inicios - como uno de las "formas de enriquecimiento de amplios sectores políticos, económicos, militares e insurgentes, convirtiéndose en un campo global que rebasa fronteras nacionales". (Valenzuela, 2003, p. 21).

La ubicación geográfica de México en relación con Centro América y en especial con Estados Unidos, implica que el fenómeno del narcotráfico deba mirarse siempre en correspondencia, ya que la gran demanda que proviene del norte se ha convertido en el horizonte de mercado para los carteles. Sin embargo, las políticas de control del consumo y del tráfico en ese país han sido ambiguas y se han centrado la mayoría de las veces en una excesiva regulación del ingreso y un débil control del consumo. Una muestra de esta regulación se ha concentrado en las fronteras y en las muchas operaciones y estrategias que se han llevado a cabo, incluso contra la soberanía del mismo México ${ }^{5}$. Puede afirmarse que la presión de Estados Unidos sobre México ha marcado decisivamente sus políticas internas de seguridad y control del narcotráfico, así, iniciativas como el Plan Mérida, aprobado por el Congreso norteamericano en 2008 aportaron más de USD 1.600 millones de dólares y convirtieron en prioridad para la presidencia de Felipe Calderón la lucha contra el narcotráfico.

En México el narcotráfico ha ido ocupando cada vez más un lugar protagónico en la vida pública y privada, hasta convertirse en un elemento característico de los análisis socio-políticos y económicos del país, especialmente, aquellos que intentan comprender y diseñar medidas que contrarresten sus efectos en la seguridad de toda la nación. Con este antecedente, no fue difícil convertir la lucha contra el narcotráfico en el principal emblema de sexenio de Felipe Calderón, que tiño la totalidad de la política de seguridad nacional. De acuerdo con Chabat este emparejamiento entre guerra contra el narco y seguridad nacional, se debió por lo menos a seis aspectos que el mandato presidencial debía enfrentar a) el extendido control del narcotráfico en diversas regiones del país. b) enfrentamiento entre cárteles que habían disparado los índices de violencia y en especial de homicidios. c) la decidida inactividad del gobierno anterior frente al narcotráfico. d) la recurrente confrontación con EEUU por la violencia en la frontera. e) el flujo permanente de droga hacia EEUU y f) el incremento en el consumo interno de droga. (2012, p. 29).

Así orientada en gran medida la función del Estado a la lucha contra el narco, prontamente el país sería protagonista de uno de los despliegues televisivos e informáticos más grandes de los últimos años ${ }^{6}$, Tv Azteca y Televisa no escatimaron esfuerzos para demostrar que la promesa de combate al narcotráfico se hacía realidad. Noticieros, entrevistas, especiales, documentales y un detallado cubrimiento en los estados donde se realizaban los operativos, contrarrestaron el clima de desconfianza en el que había sido elegido Felipe Calderón y elevaron inmediatamente su popularidad. Se expandió en el país una renovada confianza ${ }^{7}$ en los organismos del Estado y sobre todo, una fuerte convicción en la guerra ${ }^{8}$ como forma de exterminio del narcotrá-

5 Este antecedente resulta muy interesante para comprender uno de los enunciados que emergió con recurrencia en las entrevistas, relacionado con la "Operación Rápidos y Furiosos" que se llevó a cabo en las ciudades fronterizas entre México y Estados Unidos, y que visibiliza el fenómeno de incremento de armas norteamericanas vinculadas a masacres y violencia en ciudad Juárez.

6 El papel de los medios de comunicación representa un de los aspectos más importantes del despliegue del dispositivo del miedo y de su tránsito hasta convertirse en una forma de gubernamentalidad contemporánea.

7 Este sentimiento sería rápidamente desmontado por la experiencia de las comunidades que demostraban el fortalecimiento de las organizaciones criminales, su control sobre las poblaciones y el enriquecimiento de los carteles producto de la expansión del negocio de las drogas. De manera adicional, las injustificadas muertes de civiles y el hallazgo de fosas comunes de manera más recurrente, hacían más difícil sostener el discurso de una necesaria y exitosa política de seguridad. 
fico y recuperación de la seguridad. Los violentos operativos, las capturas llevadas a cabo en Chihuahua, Baja California, Sinaloa, entre otros, se convirtieron rápidamente, de la mano del enunciado daños colaterales, en el signo que habría caracterizar el sexenio. Este momento de efervescencia, detonado por la aparente eficacia de la estrategia contra el narcotráfico, resultó fundamental para comprender la forma en que fueron configurándose los espacios de seguridad fundamentados en el miedo, especialmente, en ciudad Juárez.

Los espacios de seguridad implican fundamentalmente dominios sobre el territorio y la población, para lo cual se precisa de la configuración de un medio en tanto dominio sobre las causas y los efectos y su correlato en los procesos de intervención, que permita en este caso, inscribir al país en un juego de verdad definido en función de la guerra como única alternativa. Para lograr este cometido se requerían al menos dos requisitos importantes, primero, allanar el terreno para las reformas legales e institucionales que ameritaba un estado de guerra, segundo, convencer a las poblaciones sobre la necesaria adopción de restricciones y condicionamientos para que la operación de lucha contra el narco se hiciera viable. ¿Cómo fue esto posible? ¿Qué apego, que mecanismo de adhesión logró que las poblaciones se inscribieran en el discurso de la guerra?

Podría afirmarse que el estado de indefensión en que las comunidades se encontraban, los abusos, sometimientos y vejámenes a los que estaban avocados cotidianamente constituían un factor de crisis importante que las dejaba en suficiente condición de vulnerabilidad y a total disposición para una oferta de "salvación" proveniente del Estado. Pero esto no era suficiente, se requería la apelación a una fuerza de carácter histórico que lograra la adhesión y el compromiso de transformación de las prácticas cotidianas en espera de lograr la seguridad, protección y justicia que provenía del Estado. Es así como emerge en los discursos gubernamentales y posteriormente cobra relevancia entre las comunidades, el enunciado "Espíritu de la Revolución"9 como llamado a una fuerza histórica con inconmensurable capacidad de alcanzar los más sentidos propósitos.

El Plan de Desarrollo Nacional 2007 - 2012 contemplaba cinco (5) ejes como prioritarios para el país. Estado de derecho y seguridad, economía competitiva y generadora de empleos, igualdad de oportunidades, sustentabilidad ambiental y democracia efectiva y política exterior responsable y como una de sus estrategias, la realización de un "extenso programa cultural con motivo del bicentenario de la Independencia y el centenario de la Revolución" (2007, p. 228). Pero el ascenso de esta intención a la condición de enunciado, comienza en el año 2009, cuando la lucha contra el narcotráfico ya empezaba a mostrar sus desgastes y las conmemoraciones del Bicentenario de la independencia y el centenario de la Revolución proyectadas para el 2010 permitían avivar el espíritu nacional.

Los discursos del presidente Felipe Calderón a través de diversos medios, exhortaban a renovar la confianza en el Estado y en su compromiso con la seguridad pública, conmemorar el Bicentenario y el Centenario de la Revolución, significa, por una parte, recordar lo grande que es esta Nación, lo privilegiados que somos los mexicanos por tener una historia como la que tenemos, pero, sobre todo, es una llamada a los mexicanos, a que por encima de nuestras diferencias, entendamos interno, implicó un giro importante en los procesos de gubernamentalidad que reinstaló el miedo como emoción generalizada en la población, al tiempo que permitió la configuración de nuevos escenarios de uso y abuso del poder por parte de las fuerzas del Estado. En términos del dispositivo de miedo que se intenta describir, este aspecto constituye una de las discontinuidades que expresa el soporte con los demás rasgos.

9 Archivo Gubernamentalidad México-Recurrencia Revolución_AGMRR-1 
que por encima de eso y de ser panistas, priistas, perredistas, católicos, cristianos, judíos, de tener diferentes maneras de pensar, de sentir, somos mexicanos, y que la Patria nos une, nos debe unir. ${ }^{10}$

En sucesivas formas, se ratifica que la conmemoración de la Revolución constituye un momento propicio para la unión y el orgullo nacional

Y me parece que eso [celebrar] no va en demérito del reconocimiento de los gravísimos problemas que tenemos. Yo pienso que, no sólo como cualquier otro país que tiene problemas más o menos intensos, sino como la historia misma de México, nunca hemos estado exentos de desafíos, sería absurdo que lo hubiéramos estado $y$, sin embargo, nuestra historia va avanzando. Nos hemos consolidado como un gran pueblo, que tenemos muchos logros, tenemos muchas cosas de lo cual estar orgullosos, principalmente de ser mexicanos. [...] Y eso es lo que estamos haciendo ahora, en esta oportunidad inigualable de celebrar 200 años de Independencia y 100 de Revolución_AEFC5.

Esta apelación al nacionalista espíritu de la Revolución provoca en el caso de México y de sus pobladores un profundo poder de adhesión, difícilmente comparable con otros países de América Latina, es quizá por ello que en diferentes momentos renace como un enunciado que climatiza y sintoniza las mentalidades y las acciones de la sociedad. Para Monsivais la fuerza de este enunciado radica en que en él las masas encuentran "el círculo de la seguridad, la compensación que transmuta los grandes valores (patria, historia, religión, habla, costumbres, sensaciones utópicas) en las disposiciones de la vida cotidiana" (2008, p. 159)

En adición a lo anterior, puede señalarse que uno de los rasgos distintivos de la gubernamentalidad del miedo en Ciudad Juárez, está referido a las formas de normalización de la población y a los mecanismos mediante los cuales la crisis limitó los derechos de los habitantes. Y es que para el 2012 Juárez había experimentado años de dramática violencia producto de las dinámicas del narcotráfico, la precarización de la economía, el incremento de las desigualdades sociales, la falta de oportunidades, la emergencia de grupos armados conformados por exmilitares y la explosión de diversas formas de delincuencia, todos estas condiciones habían generado un altísimo número de muertes y un fenómeno por el que la ciudad se había convertido en foco de las miradas internacionales, el feminicidio. Es por ello que ciudad de Juárez constituye uno de los casos más ilustrativos y dramáticos del conflicto nacional y uno de los escenarios donde se experimentaba para el periodo 2010-2015 un mayor sentimiento de miedo en la población.

Esta situación estaba agravada con la progresiva desaparición del modelo maquilador, el que fuera en antaño una de las fuentes económicas más importantes de la ciudad y la región de la frontera, se había reducido progresivamente por la crisis económica mundial y las mutaciones en el modelo de producción. Esta condición de desempleo e incertidumbre económica que cada vez experimenta un número mayor de pobladores de la ciudad, ha representado un nicho fecundo para la expansión del narcotráfico y la violencia, la venta, transporte y comercio de droga, tanto como para las actividades directas e indirectas que a ella se refieren.

Para el periodo 2010-2015, esta confluencia de factores y dos singularidades, provocarían un rápido volcamiento de la atención internacional y un despliegue de accio- 
nes estatales que configurarían un aspecto importante del dispositivo de miedo en la ciudad. La primera de ellas estaba asociada al creciente número de feminicidios ocurridos en Juárez, ya que contrario a la idea que se trata de eventos desligados y de fuero privado, los feminicidios han resultado cardinales en la comprensión de la violencia estructural de la región, toda vez que revelan las configuraciones socio-políticas y económicas que hacen posible la pervivencia del conflicto en Juárez y en el país. De acuerdo con Monárrez" "El feminicidio es una constante en Ciudad Juárez, [...] por lo que se requiere de estrategias de investigación, prevención, sanción y erradicación de esta violencia letal dirigida a niñas y mujeres económicamente marginales" (2009, p. 56).

Los gobiernos locales y nacionales han desconocido insistentemente la gravedad de la situación de vulnerabilidad, violación de derechos humanos, desaparición y exterminio de niñas, jóvenes y mujeres adultas en la ciudad, lo que hace más espinoso el estudio del fenómeno y ha obligado a investigadores y académicos a visibilizar las cifras, causas y condiciones en que han desaparecido y en las que han hallado los cadáveres de las mujeres, como una alternativa contundente que permita instalar el debate en las agendas públicas. Tal es el caso del Sistema de Información Geográfica de la Violencia en el municipio de Juárez, Chihuahua: Geo-referenciación y su comportamiento espacial en el contexto urbano y rural (SIGVIDA) desarrollado por Monárrez y Cervera (2010), investigadores de El Colegio de la Frontera Norte - COLEF. La base de datos que contiene el Sistema cuenta con información de 442 víctimas y muestra una clasificación de los feminicidios y de los asesinatos de niñas y mujeres así: feminicidio íntimo, infantil, familiar, por ocupaciones estigmatizadas y feminicidio sexual sistémico. De manera complementaria para el 2010 datos de la Fiscalía General de Chihuahua, la Procuraduría General de la República y la Comisión Nacional para Prevenir y Erradicar la Violencia contra las Mujeres, señalaban que la cifra de 306 feminicidios ocurridos para ese año era la más alta en los últimos 18 años.

La segunda singularidad, está asociada a la masacre ocurrida el 30 de enero de 2010 en Villas de Salvárcar, hombres armados incursionaron en la colonia y asesinaron a 15 personas de las cuales 12 eran jóvenes que celebraban un triunfo deportivo y el cumpleaños de uno de sus compañeros. Los homicidios ocurrieron en momentos de agudas y permanentes confrontaciones entre grupos criminales, pero lo que indignó a la población y activó las alarmas fueron las opiniones que sobre el hecho realizó el entonces ya desacreditado presidente Calderón. Según él se trataba de jóvenes pandilleros que se habían enfrentado a otras bandas por control del territorio. Pero esto sería solamente el comienzo de una larga serie de circunstancias que harían emerger las líneas de veridicción y jurisdicción del dispositivo de miedo que ya estaba en operación.

En breve, Juárez fue ocupada masivamente por fuerzas de seguridad mexicanas, especialmente fuerzas armadas, policía federal y fueron reforzadas otras instancias del Estado como la Procuraduría General de la República, tal presencia suponía una posibilidad de regular la inseguridad producida por narcotráfico y en general por la criminalidad y aumentaría la percepción de presencia y protección del Estado con su consecuente incremento en la seguridad de la población. De acuerdo con Chabat "la presencia de militares en las zonas de conflicto por presencia de carteles, si bien lograron reducir de manera inmediata la presencia del narcotráfico, también provocaron lo que algunos llamaron el "efecto cucaracha", el cual consistía en el desplazamiento de la narcoviolencia de un estado a otro" (2012, p. 30)

11 Peritaje sobre Feminicidio Sexual Sistémico en Ciudad Juárez. Caso 12.498. "González y otras vs México" Campo Algodonero. Presentado ante la Corte Interamericana de Derechos Humanos. Santiago de Chile, Abril 20 de 2009. 
Contrario a la idea de mayor seguridad, militares y policías rápidamente se verían involucrados en el incremento de la violencia, la violación de derechos humanos y especialmente, en la desaparición y tortura de ciudadanos juarenses. De acuerdo con el Informe de la Oficina en Washington para Asuntos Latinoamericanos - WOLA ${ }^{12}$

El aumento en el número de violaciones a los derechos humanos por parte de las fuerzas armadas es preocupante, sobre todo porque los soldados mexicanos rara vez son investigados y juzgados por los abusos que cometen y los pocos casos que resultan en acciones judiciales son atraídos por las autoridades militares en lugar de las autoridades judiciales civiles" (2010, p. 9)

A partir de estas singularidades y producto del miedo difundido por las acciones militares que se sumaban a las de recrudecimiento de la violencia por parte de los carteles del narcotráfico, se configuraron en ciudad Juárez, nuevos códigos de comportamiento, nuevas costumbres y formas de enfrentar la cotidianidad, se limitó significativamente la movilidad de los pobladores, especialmente de niños, niñas, jóvenes y mujeres. Los hombres se enfrentaban a los permanentes levantones y a los abusos de la autoridad militar que implicaban en muchos casos falsas acusaciones, torturas y desapariciones. Y las niñas, jóvenes y mujeres desaparecían en confusos hechos en los que se implicaba a la fuerza pública.

El caso de Ciudad Juárez demuestra como una línea de fuerza impuesta a través del exterminio, silenciamiento, parálisis y confinamiento de la población, se elevó como normalidad, regulación y limitación de los derechos, una gubernamentalidad instalada a partir del miedo generado por el Estado y diversos actores al margen de la ley.

\section{Medellín, ¡Tanta promesa de seguridad y protección, es la que nos da miedo! ${ }^{13}$}

La década de los 80 representó para Colombia uno de los momentos de crisis social y deslegitimidad política más graves de la historia reciente, con efectos que perduran en la vida política del país y especialmente de Medellín. La convergencia de conflictos territoriales, sociales y políticos de larga duración, con la participación de diversos actores, convertían al país en un escenario de desesperanza y a la ciudad en referente de miedo y muerte.

Como respuesta a la aguda crisis, los años 90 concretaron la idea de una nueva constitución como expresión de un renovado contrato social que permitiera levantar al país sobre un nuevo proyecto de nación basado en ideales de justicia, equidad y pluralidad y primacía de los derechos humanos. La conformación de la Asamblea Nacional Constituyente se hizo efectiva, dando paso a la construcción de una nueva carta nacional.

La Constitución de 1991 representa la expresión más reciente de refundación del Estado en Colombia, en tanto Estado social de derecho. Este nuevo pacto social fue el resultado de una movilización social, liderada por estudiantes y fuerzas políticas que demandaban una reforma radical del Estado. El momento de efervescencia política inusitado en el país, había sido motivado además por los recientes diálogos de paz que concluyeron con la incorporación a la vida pública del M-19 y detonó una amplia participación de sectores tradicionalmente marginados de la escena política. Sin embargo, la constitución y los enaltecidos ánimos ciudadanos que su promulgación generó en la década de los 90, no se compadecían con el desbordado incremento de la violencia y la reinstalación del miedo como aspecto cardinal de la

12 Abuso y miedo en Ciudad Juárez, un análisis de violaciones a los derechos humanos cometidas por militares en México. 
gubernamentalidad del país. Esto puede asociarse al menos a tres factores; 1.) La consolidación del poder económico del narcotráfico extendido ya en gran parte del territorio nacional y con capacidad de permear todas las clases sociales, incluyendo de manera especial a la clase política del país. 2.) El fortalecido combate de los grupos guerrilleros contra el Estado que elevó dramáticamente la cifra de muertos y víctimas en el país. Durante esos años, grupos como el ELN y las FARC ratificaron su dominio en las zonas agrícolas más productivas del país y acrecentaron su capacidad económica a través de prácticas de secuestro, extorsión y vinculación con el narcotráfico, lo que agudizó el fenómeno del desplazamiento y profundizó la crisis humanitaria que ya vivía el país. 3.) El surgimiento del paramilitarismo que se convertiría en uno de los actores más infaustos en la escena del conflicto colombiano. En 1994, durante la presidencia de César de Gaviria (1990-1994) se dio vida a las cooperativas de vigilancia y seguridad privada mediante el decreto 365 de 1994 y en 1995 en el mandato de Ernesto Samper (1994-1998) se les implementa bajo el nombre de CONVIVIR. Este modelo de seguridad privada, asociado a la defensa de los territorios agrícolas de influencia guerrillera, sería el preámbulo para que gremios económicos y poderes políticos en las regiones, patrocinaron la creación grupos armados entrenados con técnicas de alta milicia, cuya función era la erradicación de la guerrilla en el país, producto de su acción, las masacres se hicieron comunes y la tortura, los homicidios, aumentaron significativamente los desplazamientos y el país se enfrentó a un vertiginoso y doloroso incremento de la violencia. Este evento constituye hoy por hoy una de las líneas de fuerza más importantes del dispositivo de miedo en Colombia, ya que demuestra su uso político estratégico en la gestión de la vida pública y privada de las poblaciones.

Los años 90 se desarrollaron de un lado, en medio de un orden normativo progresista, actualizado con base en las más modernas expresiones del derecho constitucional, que consagraba un amplio espectro de derechos e instrumentos novedosos para su protección, que estimulaba la participación ciudadana renovando las formas democráticas de organización de la vida política, y de otro lado, el Estado se mostraba cada vez más desvalido para afrontar la situación de violencia extrema que vivía el país. Se hacía evidente un proceso de desestatalización de la fuerza, la soberanía y la capacidad de protección de las poblaciones, algunos autores han afirmado incluso para ese momento una condición de Estado fallido ${ }^{14}$ en Colombia.

En respuesta a la sistemática deslegitimación, los gobiernos exhibían una tendencia proteccionista de los sectores económicos a través de reformas constantes a la carta constitucional e importantes indultos tributarios a las compañías extranjeras; al tiempo que demostraban una total subordinación a lineamientos internacionales, en su mayoría condicionados por grandes préstamos que acentúan la deuda externa o que condicionan al país en el desarrollo de políticas de seguridad o lucha contra el narcotráfico.

Para comienzos del siglo XXI era innegable la connivencia entre el narcotráfico y sectores de la clase dirigente ${ }^{15}$, entre la guerrilla y el narcotráfico, entre la delincuencia y el narcotráfico, entre el paramilitarismo y las fuerzas de seguridad del Estado, todos ellos en un flagrante despliegue de estrategias basadas en el miedo para controlar las poblaciones y gestionar sus proyectos políticos, un panorama que no dejaba muchas opciones para la sociedad civil, en especial aquellos sectores que denunciaban los niveles de penetrabilidad del narcotráfico en todos los ámbitos de $14 \mathrm{El}$ portal Found for Peace, señala que para el 2013 Colombia se encontraba en el ranking 57 de 178 con un puntaje de 83.8 sobre 120. http://global.fundforpeace.org/

15 Entre 1990 y 2010 cinco mandatarios que han llegado a la casa de Nariño han sido muestra de gobiernos corruptos, arbitrarios y débiles en su función política. 
la vida del país; las consecuencias que ello tenía en materia de gobernabilidad y el importante papel que para entonces jugaba en paramilitarismo en el desbordamiento de la violencia fratricida que caracterizaba el conflicto interno. La primera década del siglo reportaba una horrorizante cifra de 5.422 .136 víctimas, producto de las muertes sistemáticas de periodistas, estudiantes, activistas de derechos humanos, líderes comunitarios, indígenas, afrodescendientes y un sinnúmero de masacres en lo ancho y largo de Colombia que ha provocado un fenómeno de destierro solo comparable con algunos países de África.

Ahora, este antecedente ilustra al menos dos importantes elementos del dispositivo de miedo que se afincó en Colombia y de manera particular en Medellín en relación con los espacios de seguridad y los medios en los que se inscribe su acción reguladora. 1.) La incapacidad del Estado para proteger y generar condiciones de justicia, bienestar y equidad para la población, es sustituida por un ejercicio arbitrario, corrupto, militarizado y securitizado de la vida cotidiana basado en el miedo. Es decir, en respuesta a la violencia estructural que ha ocasionado la disfuncionalidad del Estado y que ha generado en la sociedad colombiana desesperanza, incertidumbre y miedo, emerge la idea de la seguridad como promesa de salvación.

Este fue el espíritu que inspiró la política de seguridad democrática instaurada durante los mandatos uribistas (2002-2006 y 2006-2010) y que rápidamente fue acogida como la única salida a la crisis del país. Es importante señalar que no sólo se trató de una política de gobierno sino de un nuevo régimen económico, político y socio-cultural que polarizaría y complejizaría aún más el estado de confusión y terror que vivía Colombia. Para Autores como Angarita (2010, 2012, 2013) que ha profundizado ampliamente en el tema, la seguridad democrática "no es más que la parte visible del iceberg que se propuso allanar el camino para instaurar un régimen político bonapartista, que a su vez aseguraba la expansión o consolidación del modelo económico" (2012, p 284). Según Angarita, fueron cuatro las principales características del régimen bonapartista uribista con las cuales se condicionó el desarrollo del modelo de Estado Social de derecho: concentración de los poderes públicos y eliminación o subordinación de los órganos de control, profundización del reformismo neoliberal, prácticas autoritarias que encuentran en la seguridad democrática un pretexto para usar las vías de hecho y pretensión de instalar a toda costa un pensamiento único de adhesión al régimen (2012, p. 34).

Es innegable que un régimen como este sólo podría instalarse un medio alimentado por el miedo y la incertidumbre, ya que no solamente fue acogido por las clases dirigentes del país que encontraron en él un respaldo para la participación en el gran negocio de la guerra a través de la seguridad privada y un sendero de impunidad que les permitía avanzar en su lucrativa relación con el narcotráfico; también los sectores sociales más empobrecidos hallaron en el enunciado de la seguridad democrática, en su formas de veridicción de la realidad y en la figura de Álvaro Uribe, la respuesta de cambio que ansiaban, de ahí el amplísimo reconocimiento, apoyo y favoritismo alcanzado por el gobierno y por cada una de las reformas jurídicas y prácticas de control y securitización que se realizaron.

Intencionalmente, el enunciado de la seguridad democrática se empleó como manto de distracción para las recurrentes reformas realizadas en materia de derechos y desmonte de la forma de Estado de derecho consagrado en la Constitución. Se promulgó la idea de Estado comunitario y luego de Estado de opinión como superación del Estado de derecho (Angarita; 2012) ocultando las trasformaciones jurídico-ad- 
ministrativas, económico -sociales y específicamente poblacionales que estaban en juego detrás de la prometida seguridad. Es por ello que, interpretado en clave foucaultiana, el enunciado de la seguridad democrática uribista trabajó, fabricó, organizó y acondicionó un medio (Foucault, 2007, p. 41) que hiciera efectiva la transición sin oposición de las mayorías.

El segundo aspecto está relacionado con 2.) El narcotráfico que ha penetrado las fibras del sistema político, que ejerce control sobre las poblaciones a través de las redes criminales y paramilitares, interviniendo la vida pública y privada en cada territorio. Se trata de una singularidad que amplía la idea de poder soberano expuesta por Foucault (2007) en el dispositivo de seguridad, instalándola en otros actores sociales. Es decir, lo que devela la irrupción del narcotráfico en la vida política colombiana, es la presencia de otro poder soberano con capacidad de intervenir territorios, cuerpos y poblaciones; de fijar fronteras, definiendo modos de acción de los sujetos, circulación productos y ordenamiento del territorio. Con la misma y a veces mayor capacidad de organización del territorio, de generación de la guerra y regulación de la paz, el narcotráfico configura un espacio de soberanía que mediante el miedo y como afirma Foucault "produce un cierre circular de los efectos y las causas, porque lo que es efecto en un lado se convertirá en causa de otro" (2007; p. 41) generando una forma de poder que suplanta la del Estado.

La expansión del narcotráfico en Colombia a partir de los años 80 y del poder económico, político y bélico del cartel de Medellín bajo la dirección de Pablo Escobar demostró que se trataba más que de un sector de la delincuencia, de un actor con capacidad de competir con la fuerza, autoridad y soberanía del Estado. Luego de la muerte de Escobar, La Oficina de Envigado en cabeza de Diego Fernando Murillo Bejarano - Alias don Berna - que para entonces fungía como líder desmovilizado del bloque Cacique Nutibara de las autodefensas unidas de Colombia, coopta la totalidad de los negocios del cartel y establece un control sobre toda la ciudad a través de las bandas delincuenciales, un proceso que sumergió a Medellín en una nueva ola de violencia y homicidios. El conjunto de estrategias de control sobre el negocio de las drogas, la extorsión, el secuestro, el robo y otros delitos devino en una hegemonía que fue denominada por algunos académicos y periodistas de la ciudad como "donbernabilidad".

Aunque el término generó profundos rechazos, las investigaciones de ONG como el IPC, Corpades, Corporación Jurídica Libertad, Corporación viva la ciudadanía y Corporación Región entre otras, develaron que además del esfuerzo de control absoluto por parte de La Oficina, existía un pacto con las autoridades municipales y miembros de la iglesia católica para que esta hegemonía deviniera en reducción de la violencia y pacificación de la ciudad. Aunque la versión ha sido desmentida en reiteradas oportunidades, lo que las investigaciones revelan es que existen antecedentes de pactos de estas magnitudes que en su momento han librado a Medellín de confrontaciones armadas y muertes masivas, y que no obedece a una expansión de la soberanía del Estado, ni mucho menos a una eliminación o sometimiento de los grupos ilegales como se ha divulgado en medios.

Lo que los pactos, en su aspiración resolutoria del gobierno sobre el territorio, develan en clave foucaultiana, es la formalización de la desestatización de la soberanía y una distribución de la gubernamentalidad por incapacidad de dominación y sometimiento por parte del poder legítimo del Estado. Un juego de poder que instala nuevos regímenes de prácticas y nuevas racionalidades para operar la vida cotidiana. 
Es por ello que puede afirmarse que la "donbernabilidad" se estableció como una forma de gobernabilidad en paralelo y que en gran medida viabilizó los procesos administrativos y de gestión que tenía trazada la ciudad.

Ahora, ¿por qué es importante problematizar esta forma de gobernabilidad en el dispositivo de miedo? En primer lugar porque se trata de una racionalidad que opera con prácticas de terror y amedrentamiento como forma de regulación de su estructura criminal y también de las poblaciones. Pero además, porque las prácticas están articuladas, emergen y se desarrollan a modo de red, para lograr efectos en la ampliación de sometimiento y a su vez como expansión de los intereses económicos que le definen. Y finalmente, porque esta forma de gobernabilidad marca una distancia con la idea foucaultiana del dispositivo de seguridad a partir de un cierto control unitario por parte del Estado. En el dispositivo de miedo, una de las características fundamentales será la multiplicidad de fuentes de las que deviene el miedo y los diversos regímenes de enunciación, veridicción y racionalización de los que proviene el gobierno sobre los hombres.

Otro aspecto interesante de esta simultaneidad gubernamental del dispositivo de miedo que queda develada con la "donbernabilidad" es la diversidad de tecnologías de gobierno que son aplicadas a las poblaciones. Es decir, al operar coexistentemente las poblaciones han de consentir las prácticas de sometimiento y asumirlas como reglas de existencia. De un lado, las del Estado, con sus regímenes de control jurídico y penal y de otro las de la criminalidad con sus necrotecnologías, que acorralan y atrapan a los sujetos.

Esto abre una nueva discusión respecto de la irrefutabilidad de la dominación y a la condición de atrapamiento que han experimentado las poblaciones de Medellín, frente a lo que habría que decir, consistente con la categoría analítica de dispositivo y es que aunque el sometimiento sea el fin último de las tecnologías de gobierno, estas siempre se mueven en una condición - por más reducida que parezca- de juego de poder, valga decir, en un juego que deja abierta la posibilidad de fuga, resistencia y ruptura. Un aspecto que se problematizó ampliamente la investigación y que será materia de nuevas publicaciones.

\section{Gubernamentalidad del miedo en México y Colombia ¿una expresión Fobopolítica?} Intentando seguir el método definido por Foucault para la que denominó historia crítica del pensamiento, la investigación mantuvo la esencia del ejercicio arqueológico, especialmente en lo relacionado con la tarea de eventualización y problematización. Apropiada de esta caja de herramientas, la investigación avanzó decididamente a partir del corpus teórico sobre el miedo y sobre el archivo conformado por los enunciados y visibilidades derivados de sus usos políticos en los contextos de ciudad Juárez en México y Medellín en Colombia subrayando como conclusión que se trata de una forma contemporánea de gubernamentalidad que puede denominarse como Fobopolítica.

Ha sido precisamente el uso de las estrategias analíticas las que han permitido concluir que no se trata sólo de un elemento de la política, el miedo es un dispositivo capaz producir una dinámica de entrecruzamientos haciendo emerger objetos, conocimientos, realidades que de otra manera no podrían existir. Al operar como dispositivo, el miedo adquiere una capacidad productiva, creativa y recreativa inusitada y convirtiéndose en una especie de escenario con el que se estructura y produce una particular skenographia epistémica, estética, ética y política. 
Al comprenderse el miedo como un dispositivo, ha sido posible profundizar en las relaciones de poder, las producciones discursivas y no discursivas, tanto como en los procesos de subjetivación, esto es, interpretar los efectos que en términos de gubernamentalidad ha tenido el miedo para el caso de Juárez y Medellín, y colegir comprensiones de mayor raigambre, relacionadas con aquello que Foucault denominara gobierno de los hombres en la política contemporánea. Así, interrogando los discursos, relaciones de poder y procesos de subjetivación en relación con el miedo y sus usos, fue posible hacer visible otras líneas de gubernamentalidad entre las cuales se tejen las vidas de hombres y mujeres, especialmente jóvenes en México y Colombia y que para efectos de producción académica enunciaremos como Fobopolítica.

Pero ¿Qué significa este giro? La investigación comenzó con la pregunta ¿Cómo ha llegado el miedo a convertirse en el aspecto definitorio de los procesos de gubernamentalidad en México y Colombia? Esta fundada en una sospecha acerca de que la expansión del miedo y sobre todo en la densidad con la que se experimenta en la vida de las personas, podría estar asociado más a un origen externo al sujeto que a condiciones individuales y psicológicas de difícil resolución. Pues bien, el uso de la categoría dispositivo de miedo en el caso de México y Colombia, permitió hallar esas fuentes en el Estado, en los poderes paraestatales, el narcotráfico, la violencia y la criminalidad, pero sobre todo permitió visibilizar que las prácticas discursivas y no discursivas que producen el miedo y que normalizan el mundo a través de él, expresan en lo local relaciones de poder/saber que devienen de dinámicas globales. Estas dinámicas rubrican los modos de ser y hacer, regímenes de veridicción y jurisdicción que instalados en el sujeto, devienen en un nuevo dispositivo de autoproducción de la subjetividad. De ahí que la Fobopolítica emerja como una posibilidad de comprender la gubernamentalidad del miedo, no solo desde su origen externo, sino como una forma de coproducción entre el sujeto y las formas de poder/saber de la política contemporánea (Agudelo, 2011).

\section{Referencias}

Abello, A., \& Angarita, P. E. (2013). Nuevo pensamiento sobre la seguridad en América Latina: hacia la seguridad como valor democrático. Medellin, Colombia: CLACSO

- Observatorio de Seguridad Humana. http://biblioteca.clacso.edu.ar/clacso/ gt/20131024032127/NuevoPensamiento.pdf

Angarita, P. E. (2011). Seguridad democrática, lo invisible de un régimen político y económico. Bogotá: Siglo del Hombre Editories. http://www.jstor.org/stable/j. $\underline{\mathrm{ctt} 14 \mathrm{bs} 5 \mathrm{bt}}$

Angarita, P. E., Gallo, H., \& Jiménez, B. (2008). Dinámicas de guerra y construcción de paz. Estudio interdisciplinario del conflicto armado en la comuna 13 de Medellín. Medellín: Universidad de Antioquia, Universidad de Medellín, Corporación Región e Instituto Popular de Capacitación. http://repository.udem.edu.co/handle/11407/2668

Arendt, H. (2012). Los hombresyel terror. Buenos Aires: RBA pensamiento.https://www. casadellibro.com/libro-los-hombres-y-el-terror/9788490062999/1984950

Bauman, Z. (2007). Miedo líquido, la sociedad contemporánea y sus temores. Barcelona: Paidós. https://www.casadellibro.com/libro-miedo-liquido-la-sociedad-contemporanea-y-sus-temores/9788449319846/1127467 
Beck, U. (2006). La sociedad del riesgo global. Madrid: Siglo XXI. http://davidhuerta. typepad.com/files/beck-ulrich-la-sociedad-del-riesgo-hacia-una-nueva-modernidad.pdf

Carrion, F., \& Damert, M. (2009). Economía política de la seguridad ciudadana. Quito, Ecuador: Flacso. https://www.flacso.edu.ec/portal/publicaciones/detalle/ economia-politica-de-la-seguridad-ciudadana.3792

Centro de Estudios por la Paz J.M Delás. (14 de noviembre de 2010). Militarismo en América Latina: Cuaderns per a la solidaritat. Obtenido de www.justiciaipau.org: http://www.centredelas.org/images/stories/adjunts/663 Militarismo20Lati$\underline{\text { na cas.pdf }}$

Chabat, J. (2012). La respuesta del gobierno de Felipe Calderón al desafío del narcotráfico: entre lo malo y lo peor. En A. A. Serrano, Los grandes problemas de México. Seguridad nacional y seguridad interior. (pág. 361). México: Colegio de México. http://www.jstor.org/stable/j.ctt1657t6f

Chakrabarty, D. (2000). Provincializning Europe: postcolonial thougtt and historical difference. Princeton : Princenton University. http://press.princeton.edu/titles/8507.html

Delemeau, J. (2002). El miedo en occidente. Buenos Aires: Taurus. https://www.casadellibro.com/libro-el-miedo-en-occidente/9788430609079/1958410

Deleuze, G. (2013). El Saber. Curso sobre Foucault. Tomo I. Buenos Aires: Editoral Cactus. https://www.casadellibro.com/libro-el-saber-curso-sobre-foucault-tomo-i/9789872922405/2178180

Deleuze, G. (2014). El Poder. Curso sobre Foucault. Tomo III. Buenos Aires: Editorial Cactus. https://www.casadellibro.com/libro-el-poder-curso-sobre-foucault-tomo-ii/9789872922498/2382199

Deleuze, G. (2015). La Subjetivación. Curso sobre Foucault. Tomo III. Buenos Aires: Editorial Cactus. https://www.casadellibro.com/libro-la-subjetivacion-curso-sobre-foucault-tomo-iii/9789873831034/2551629

Foucault, M. (1982). La imposible prisión: Debate con Michel Foucault. Barcelona : Anagrama. https://monoskop.org/images/1/1b/La imposible prison debate con Michel Foucault.pdf

Foucault, M. (2004). La arqueología del saber (Primera, 1a reimpresión ed.). (A. Garzón del Camino, Trad.) Buenos Aires, Argentina: Siglo XXI Editores S.A. de C.V. https://www.casadellibro.com/libro-la-arqueologia-del-saber-19-ed/9789682315862/822762

Foucault, M. (2007). Seguridad territorio, población: Curso en el Collège de France: 1977 - 1978 (Primera, 2a reimpresión ed.). (H. Pons, Trad.) Buenos Aires, Argentina: Fondo de Cultura Económica de Argentina S.A. https://crucecontemporaneo. files.wordpress.com/2012/01/foucault michel-seguridad territorio poblacion. $\underline{p d f}$ 
Foucault, M. (2008). Nacimiento de la biopolítica: Curso en el Collège de France: 1978 - 1979 (Primera 1 a reimpresión ed.). (H. Pons, Trad.) Bueno Aires, Argentina: Fondo de Cultura Económica de Argentina. http://www.inau.gub.uy/biblioteca/seminario/nacimiento $\%$ 20biopolitica.pdf

Monsivais, C. (2008). El 68, la tradición de la resistencia. México: Ediciones Era. https:// www.librerianacional.com/pagina

Morey, M. (2014). Escritos de Foucault. México: Editorial Sexto Piso. https://www. casadellibro.com/libro-escritos-sobre-foucault/9788415601623/2263585

Morey, M. (2014). Lectura de Foucault. México: Editorial Sexto Piso. http://revistas. um.es/daimon/article/view/195531

Nussbaum, M. (2013). La nueva intolerancia religiosa. ¿Cómo superar la política del miedo en una época de inseguridad? Barcelona: Paidós. https://www.amazon.fr/ nueva

Poincaré, H. (1962). Ciencias y Método. Madrid: Ed. Esparsa-Calpe. https://www.casadellibro.com/libro-la-ciencia-y-metodo/9788423904099/261594

Restrepo, E. (2008). Cuestiones de método: eventualización y problematización en Foucault. Tabula Rasa, 111 - 132. http://www.scielo.org.co/pdf/tara/n8/n8a06.pdf

Valenzuela Arce, J. M. (2012). Sed de mal. Feminicidio, jóvenes y exclusión social (Primera ed.). Tijuana, Monterrey, Baja California, Nuevo León, México: El Colegio de la Frontera Norte, A.C., Universidad Autónoma de Nuevo León. http://www.scielo. org.mx/scielo.php?script=sci arttext\&pid=S0187-73722015000100010 